\title{
Menopause Induces Oxidative Stress
}

\author{
Claudia Camelia Calzada Mendoza and \\ Carlos Alberto Jiménez Zamarripa \\ Additional information is available at the end of the chapter \\ http://dx.doi.org/10.5772/52082
}

\section{Introduction}

\subsection{Menopause: endocrinology and symptoms}

Menopause is a physiologic process in women that occurs around 45-55 years old, which is defined as permanent cessation of menstruation by one year in row [1]. The age of menopause depends on multiple factors such as number of ovules from the female at birth, the frequency of loss of these ovules through her life and the number of ovarian follicles required maintaining the menstrual cycle. The diagnosis of menopause is retrospective and is established after a year without menses [2], and their symptoms may have different intensity for each woman [3].

This process is characterized by gradual decrease of estrogen (E) secretion and changes related with sex hormones, so that estradiol levels ranging from 5 to $25 \mathrm{pg} / \mathrm{mL}$, while increasing titers of gonadotrophins, so that the values of follicle stimulating hormone (FSH) between 40 and $250 \mathrm{mU} / \mathrm{mL}$ and luteinizing hormone (LH), from 30 to $150 \mathrm{mU} / \mathrm{Ml}[4,5]$.

Irregular uterine bleeding is a characteristic symptom which is due to both depletion and resistance of ovarian receptors to gonadotropins and increased FSH, leading to alterations in the volume and frequency of bleeding (polymenorrhea, hypo-or menorrhagia, oligomenorrhea) $[6,7]$.

Among symptoms are those related to the genitourinary tract by the common embryological origin of vulva, vagina, bladder, and urethra, consequently alterations as dysuria, urinary urgency and incontinence, epithelial atrophy, decreased production of mucus and vaginal dryness (phenomena that can cause dyspareunia), urethritis, vaginitis or cystitis and local infections $[8,9,10]$ (Figure 1). 


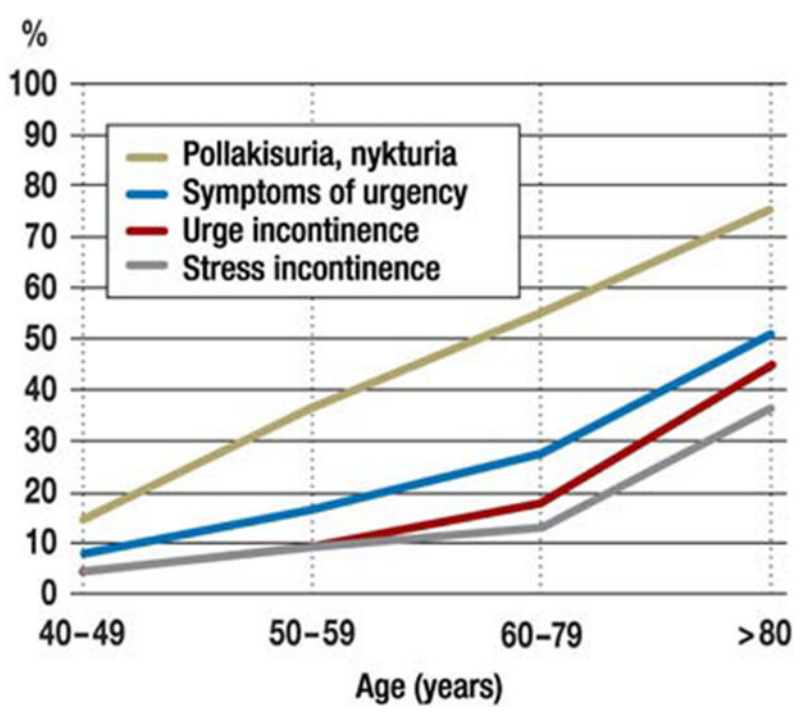

Figure 1. Main genitourinary abnormalities according to age in women [10].

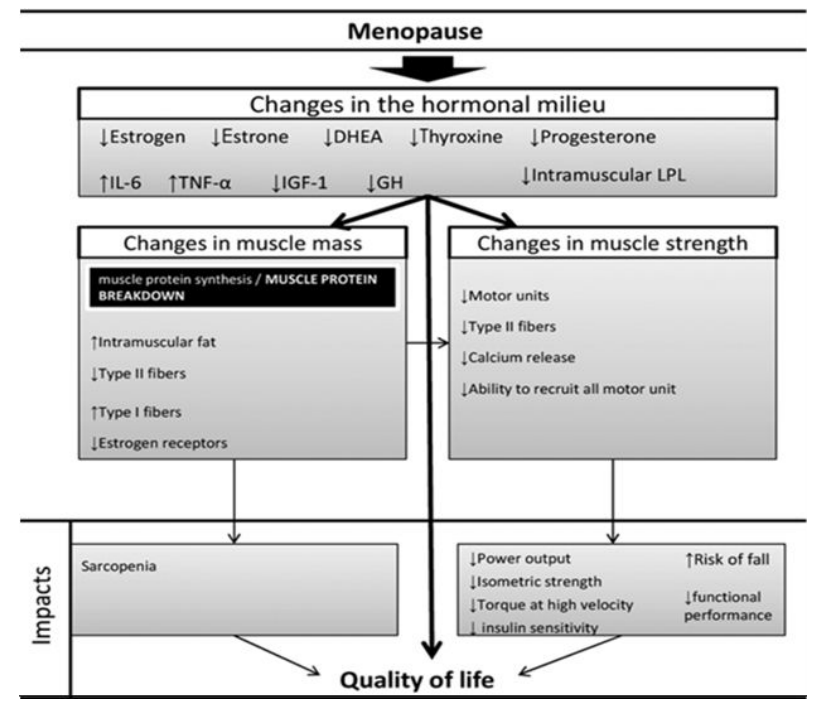

Figure 2. Changes observed in muscle mass and strength after menopause [16].

Hot flushes are one of the main symptoms associated with menopause and occur in more than $75 \%$ of menopausal, consisting of intense episodes of heat that begins on chest and spreads to face, sweating, and flushing of face. Hot flushes are associated with headache, 
anxiety and palpitations, and it usually lasts 2-4 minutes and can vary in frequency, in some women may be daily while others may have one episode per month [11, 12]. The mechanism of hot flushes is not clear, however, it is known that hypothalamus, pituitary gonadotropin releasing hormone and gonadotrophins may be involved in hot flushes [13]. Another frequent symptom is an oral dryness and intense burning sensation that affects mainly the tongue and sometimes lips and gums [14].

On the other hand decreases the content of collagen and elastic fibers of the skin, so that it becomes thinner and brittle losing elasticity and firmness. The epidermis thins, increases water loss and reduces the number of blood vessels, compromising the supply of oxygen and nutrients [15]. Additionally aging is associated with a natural decline in physiological functions, including a loss of muscle mass and strength. Overall, the decline in muscle mass averages 0.4 to $0.8 \mathrm{~kg}$ per decade, starting at the age of 20 years, especially around menopause [16] (Figure 2).

Another alteration that occurs is the osteoporosis, which is defined as a skeletal disorder characterized by decreased bone density and an increased risk of fractures $[17,18]$. Before reports have confirmed that postmenopausal women have highest incidence of hip fractures $[19,20,21]$ (Figure 3).
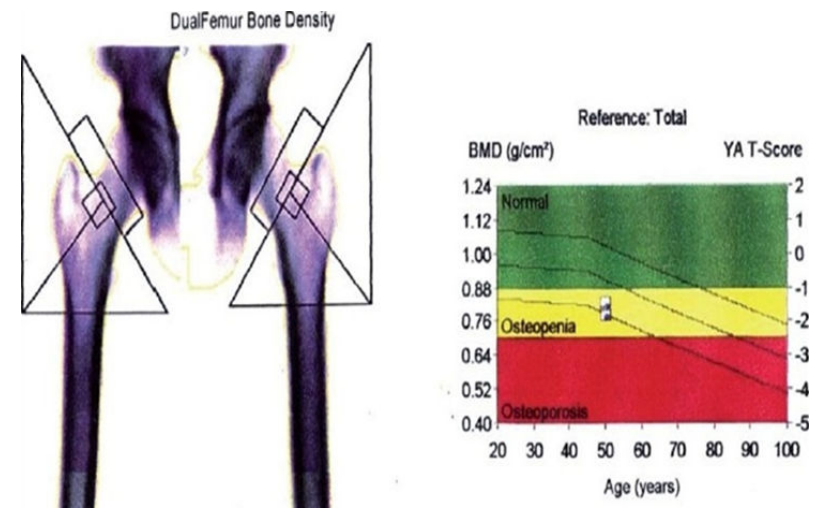

Figure 3. Bone mineral density values by age in women. Bone mineral density decreases around menopause [21].

Menopause is a stage that favors weight gain and development or worsening of obesity, and causes of this problem are many; some are clearly related to hypoestrogenism and other age-dependent, conditioning increased intake and decreased energy expenditure [22, 23] (Figure 4).

During this period there is an abnormal atherogenic lipid profile characterized by increased lipoprotein cholesterol, low density (LDL-C), triglycerides (TG) and small dense LDL particles [24] with reduced HDL-C and elevated serum glucose and insulin, perhaps as a direct result of ovarian failure or indirectly as a result of central redistribution of body fat, and this favors the formation of atheromatous plaques and progression of coronary atherosclerosis 
and therefore cardiovascular disease incidence increases substantially in postmenopausal women $[25,26]$. Other disorders such as obesity and metabolic syndrome also occurs at menopause, suggesting that menopause may be the trigger of the metabolic syndrome at that stage of life $[27,28]$.
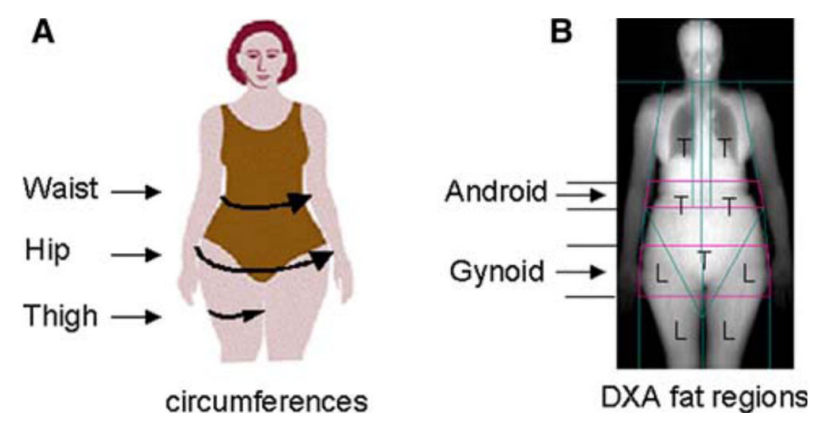

Figure 4. Body fat distribution. Android-type distribution is present in postmenopausal women. DXA= Dual-energy Xray absorptiometry [23].

Postmenopausal women have higher insulin resistance than premenopausal, which could participate to age, the increase in total body fat, central adiposity, estrogen deficiency, alterations in lipid profile and glucose homeostasis and insulin are more frequent and favor the high cardiovascular morbidity and mortality after menopause. In this sense the transition of menopause is marked by changes in hormonal balance, with increased visceral fat, which are associated with insulin resistance, although it has been found that the change in insulin sensitivity does not alter the lipid profile in early postmenopausal women [24, 26] (Figure 5).

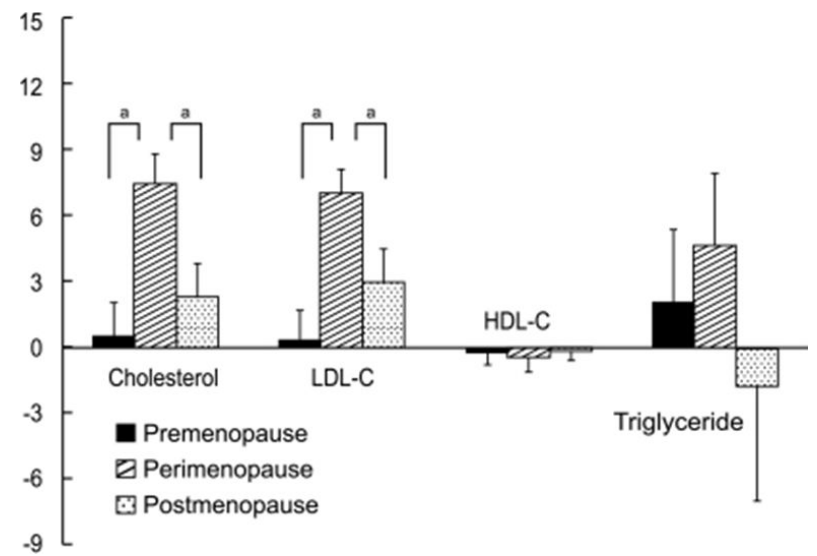

Figure 5. Changes lipid during transition from premenopause to Postmenopause [24]. 
Depression occurs frequently in postmenopausal women, which is explained by the loss of estrogenic effect in modulating neuronal excitability, synaptic plasticity, neuronal survival induced expression of regenerative responses, regional neurogenesis, regulation of differentiation and neuronal development [29], in the processes of cognition, modulation of mood and other mental states, as well as improving learning and memory [30], regulate the synthesis of tryptophan hydroxylase which is the limiting enzyme in serotonin synthesis so this decline in estrogen at menopause may explain the occurrence of psychological symptoms characteristic of depression (fatigue, irritability, sleep problems, abrupt changes of mood, [31]. With respect depressive symptoms in the Multiethnic Study of Atherosclerosis were analyzed testosterone, estradiol, steroid hormone binding globulin (SHBG) and dehydroepiandrosterone; indicating that in early postmenopausal women, sex hormones were associated with incident depressive symptoms [32].

\section{Pro and antioxidants propierties of estrogens}

Throughout menopause there are factors that predispose women to the development of oxidative stress, such as estrogen deficiency, as it has been confirmed that they have an antioxidant capacity independently of its binding to receptors, so for example the $17 \beta$-estradiol (E2), estriol, estrone, ethinylestradiol and 2-hidroxiestradiol besides reducing neuronal death with antioxidant activity, due to the presence of an intact hydroxyl group on ring A of the molecule [33].

Estrogens are synthesized from different androgen precursors such as androstenedione and testosterone, yielding as products estrone and $17 \beta$-estradiol, respectively. The synthesis is catalyzed by aromatase (ARO), the enzyme cytochrome P450 (CYP19) and estrogen synthesizing different tissue-specific manner, and the major estrogen in adipose tissue is estrone, the placenta is estriol and in cells granulosa is 17 $\beta$-estradiol [34].

The 2-hidroxiestradiol and 2-hydroxyestrone (4-hidroxiestradiol type) (Figure 6) can participate in redox cycling to generate free radicals such as superoxide and chemically reactive estrogen semiquinone/quinone, which can damage DNA and other intracellular constituents.

4-hidroxiestradiol participates in a redox cycle to generate free radicals such as superoxide, and intermediate semiquinone/quinone, these intermediaries may induce cell transformation and initiate tumoral growth [35].

4 - hydroxyestrogens have estrogenic effects and can stimulate the growth of cell lines of breast cancer, with greater intensity than the 4-hydroxyestrone are unstable and can become highly reactive quinone with the formation of semiquinones as intermediary, this reaction produces oxygen free radicals, which can have toxic effects on DNA, such effects include the formation of 8-hydroxy-2-deoxiguanosine a mutagen, resulting from oxidative damage. The toxic effect of 4-hydroxyestrogens probably is prevented under normal conditions intracellular defense mechanisms. Oxygen free radicals can be removed immediately transformed into water by enzymes such as catalase and superoxide dismutase and antioxidant vitamins 
such as ascorbic acid and alpha tocopherol, quinone themselves can be inactivated by sulfo compounds, such as glutathione [36].

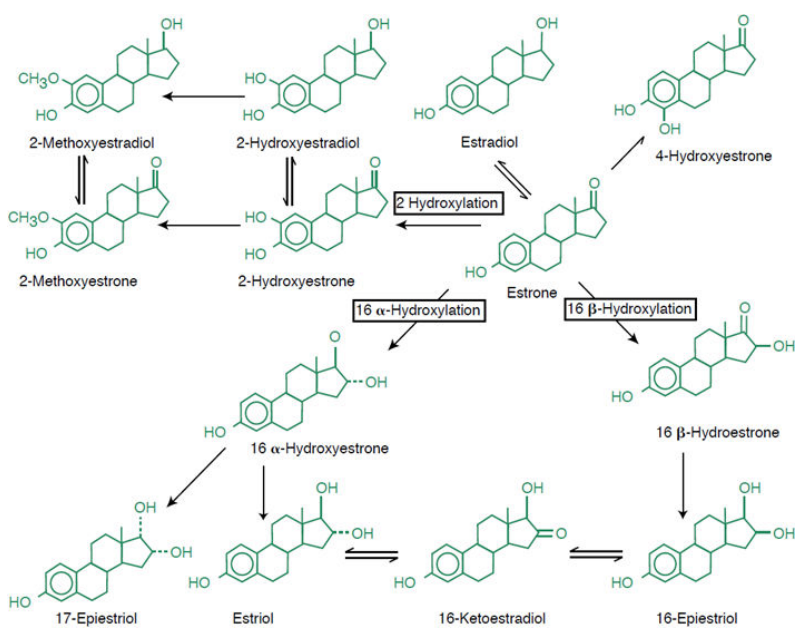

Figure 6. Estrogen metabolism.

Menopause seems to accelerate the development of atherosclerosis and cardiovascular diseases and in order to identify this correlation, was assessed the correlations between intimamedia thickness, homocysteine serum levels and oxidative stress both in fertile and postmenopausal women and it was founded that were increased levels of homocysteine, oxidative stress and intima-media tickness (IMT) in postmenopausal women having a positive correlation with IMT, which reinforce the idea that a hyperhomocysteinemia may play a role in the progression of atherosclerosisas a result the lack of estrogens [37].

Vasculo protective effects of estrogen are due in part to the modulation of the balance between nitric oxide (mainly derived from endothelial vasodilator molecule) [38] and superoxide anion (oxygen-free radical highly reactive), promoting the availability of the first such so the lack of protection induces high levels of oxidative stress and low concentrations of NO, these processes are interacting with hypertension, as seen in menopause. In addition, estrogen induces the expression of oxide reductasesthiol / disulfide, such as disulfide isomerase, thioredoxin, thioredoxinreductase and glutaredoxin in the endothelium and inhibits apoptosis mediated by hydrogen peroxide. On the other hand has been described that genetic factors related to dyslipidemia are most important than due to age, for example antioxidant enzymes (SOD, catalase, GR, inflammatory markers CPR, ALT), oxidative stress $(\mathrm{O}(2)(-)$, $\mathrm{LOO} \bullet)$, hypoxia $(\mathrm{HBNO})$ and all this related to increase vascular resistance, disorders in oxygen supply in tissue and hypoxic competitions of there metabolism may cause, postmenopausal hypertension, hart ischemic disease, impaired hepatic beta-oxidation of fatty acids and hepathosteatosis [39]. 
$17-\beta$-estradiol plays a critical role in neuroprotection through both genomic and non-genomic mechanisms and recently was discovered that a new G-protein-coupled receptor 30 (GPR30) participates in the neuroprotection against oxidative insult, which is agonist G1. E2 attenuated apoptosis induced by $\mathrm{H}_{2} \mathrm{O}_{2}$ exposure, furthermore, G1 or E2 significantly increased the levels of phosphorylated extracellular signal-regulated kinase 1/2 (p-ERK1/2), Bcl-2 and pro-caspase-3, which is an anti-apoptotic effect [40].

\section{Oxidative stress and postmenopause}

Actually several oxidative stress biomarkers have been studied in menopause, however, each researcher has used different marker, methodologies and women with dissimilar characteristics (age, ethnic group, postmenopause time), fact does difficult to make a conclusion about the development of oxidative stress during peri, menopause and postmenopause.

Recently has been propose as indicator to $\gamma$-glutamyltransferase (GGT) which is an enzyme involved in the transfer of the $\gamma$-glutamyl residue from $\gamma$-glutamyl peptides to amino acids, $\mathrm{H}_{2} \mathrm{O}$, and other small peptides and can be donated by glutathione [41]. On the other hand, GGT is also involved in the production of glutathione [42], which is limited by cysteine availability. GGT participates in the pathway of extracellular GSH in consequence the biosynthesis of cellular glutathione, the most important cell antioxidant, depends of GGT activity; hence this enzyme may play an important role in the anti-oxidative defense system of the cell [43].

Abdul et al, founded a highly significant reduction in glutathione levels in the post-menopausal-group which could be due to the increase in its free radical scavenging property and increased consumption to counteract the oxidative stress and to inhibit membrane lipid peroxidation which indicates that the increase in serum GGT with enhanced oxidative stress and reduced antioxidant defense system in the post-menopausal women may lead to the speculation that GGT could be considered an index or a oxidative stress marker [43] (Table 1).

\begin{tabular}{cccc}
\hline Serum level & $\begin{array}{c}\text { Premenopausal } \\
\text { Group }(\mathbf{n = 1 7})\end{array}$ & $\begin{array}{c}\text { Postmenopausal } \\
\text { Group }(\mathbf{n}=\mathbf{1 6})\end{array}$ & p value \\
\hline GGT $(\mathrm{U} / \mathrm{L})$ & $5.96 \pm 2.99$ & $9.44 \pm 2.89$ & 0.025 \\
\hline GSH $(\mathrm{mmole} / \mathrm{L})$ & $0.62 \pm 0.17$ & $0.47 \pm 0.11$ & 0.008 \\
\hline MDA $(\mu \mathrm{mole} / \mathrm{L})$ & $1.04 \pm 0.06$ & $1.32 \pm 0.05$ & 0.035 \\
\hline
\end{tabular}

Table 1. Serum $\mathrm{y}$-glutamyltransferase, glutathione and malondialdehyde levels in the pre- and postmenopausal women [43].

Supplementary it was found that perimenopausal women have higher total cholesterol values and lower paraoxonase-1 (PON1) activity compared to reference values, 8-oxoG levels were unchanged compared with those of healthy control women, lipoperoxide ranks were 
significantly increased compared with those of premenopausal women and an indirect correlation between PON1 arylesterase (PON1 A) activity and lipoperoxide levels, between PON1 A activity and atherogenic index, between age and TAS, and between age and 8-oxoG levels. Moreover perimenopausal women had higher total cholesterol levels and PON1 A levels were lower than physiological values (table 2) [44].

\begin{tabular}{|c|c|c|}
\hline Variable & Average \pm SD or median & Physiological values \\
\hline $\mathrm{TCH}$ & $5.673 \pm 0.856 \mathrm{mmol} / \mathrm{L}$ & क्్ర.17 mmol/L \\
\hline TG & $1.424 \pm 0.66 \mathrm{mmol} / \mathrm{L}$ & $01.9 \mathrm{mmol} / \mathrm{L}$ \\
\hline LDL & $3.103 \pm 0.649 \mathrm{mmol} / \mathrm{L}$ & $2 B .5 \mathrm{mmol} / \mathrm{L}$ \\
\hline HDL & $1.563 \pm 0.445 \mathrm{mmol} / \mathrm{L}$ & 01.4 mmol/L \\
\hline $\begin{array}{l}\text { Atherogenic index } \\
(\mathrm{TCH} / \mathrm{HDL})\end{array}$ & $3.853 \pm 1.009$ & Бक्र.2 \\
\hline PON1 A & $89.628 \pm 14.798 \mathrm{U} / \mathrm{mL}$ & $100-200 \mathrm{U} / \mathrm{mL}$ \\
\hline Pon1 L & $12.213 \pm 2.956 \mathrm{U} / \mathrm{mL}$ & $13-20 \mathrm{U} / \mathrm{mL}$ \\
\hline Homocysteine & $8.48 \pm 2.97 \mu \mathrm{mol} / \mathrm{L}$ & 团 $2 \mu \mathrm{mol} / \mathrm{L}$ \\
\hline Glycemia & $5.43 \mu 0.65 \mathrm{mmol} / \mathrm{L}$ & $4.2-6.2 \mathrm{mmol} / \mathrm{L}$ \\
\hline Uric acid & 246.5 (209.9-296.9) $\mathrm{mmol} / \mathrm{L}$ & [B339 $\mathrm{mol} / \mathrm{L}$ \\
\hline
\end{tabular}

Table 2. Data showing departures from normality are expressed as median values with the respective lower and upper quartile. The boldfaced entries indicate values beyond the reference range. PON1 A, paraoxonase with arylesterase activity; PON1 L, paroxonase-1 with lactonase activity.Paroxonase-1 levels in perimenonausal women [44].

Another finding is the lipoperoxide level which was significantly increased in perimenopausal women (Table 3). The levels of the marker of oxidative damage to DNA-8-oxoG were not statistically between pre and perimenopausal. In contrast women in perimenopause had repair ability 4 times higher compared with premenopausal women and significantly increased plasma total antioxidant capacity (TAS) [44] (Table 3).

\begin{tabular}{lll}
\hline Variable & Perimenopausal women & Controls (premenopausal) \\
\hline TAS & $1.532 \pm 0.095 \mathrm{mmol} / \mathrm{L}^{\mathrm{a}}$ & $1.230 \pm 0.100 \mathrm{mmol} / \mathrm{mL}$ \\
\hline Lipoperoxides & $37.995(32.035-44.849) \mathrm{nMol} / \mathrm{mL}^{\mathrm{a}}$ & $28.096(23.103-30.850) \mathrm{nmol} / \mathrm{mL}$ \\
\hline 8-oxoG & $0.464(0.283-0.957) \mathrm{per} 10^{6} \mathrm{G}$ & $0.503(0.337-0.674) \mathrm{per} 10^{6} \mathrm{G}$ \\
\hline Repair ability & $36.919 \%(30.679 \%-47.046 \%)^{\mathrm{a}}$ & $10.539 \%(8.665 \%-11.475 \%)$ \\
\hline
\end{tabular}

Table 3. Data showing departures from normality are given as median values with the respective lower and upper quartile. athese values are significantly different (P团.005) compared with controls. Profile oxidant and antioxidant between premenopausal and perimenopausal women [44]. 
In another study were determined age, body weight, and superoxide dismutase (SOD), catalase (CAT) and malondialdehyde (MDA) in disease-free women aged 25-65 years and did found that postmenopausal women had the highest oxidative stress and body weight, also superoxide dismutase, catalase and malondialdehyde were correlated significantly with body weight [45].

Pansini demonstrated that the total body fat mass increases significantly in postmenopause in comparison with premenopause, with specific increases in fat deposition at the level of trunk (abdominal and visceral) and arms. Concomitantly, the antioxidant status adjusted for age showed that antioxidant status was retained. Also both antioxidant status and hydroperoxide level increased with trunk fat mass [46].

Also has been carried out protocols that analyze the connection between menopause and periodontal conditions, though to compare serum and gingival crevicular fluid (GCF) total antioxidant capacity (TAOC) and superoxide dismutase (SOD) concentrations in postmenopausal patients with chronic periodontitis (PMCP) with those of pre-menopausal chronic periodontitis patients (CP). The results showed Serum and GCF TAOC and SOD concentrations were significantly lower in menopause and periodontitis, the lowest values were in the PMCP group, whereas the highest values were in premenopausal. While the effect of menopause was more evident in serum antioxidant analysis, the consequence of periodontitis was observed to be more apparent in GCF and a decrease in systemic and local AO defense was observed owing to both menopause and periodontitis [47].

\begin{tabular}{|c|c|c|c|}
\hline Risk factor & OR & $95 \% \mathrm{Cl}$ & $\mathbf{P}^{\mathbf{a}}$ \\
\hline Menopause (hypoestrogenism) & 2.62 & $1.35-5.11$ & 0.005 \\
\hline Consumption of alcoholic beverages ( $\geq 2$ glasses/d) & 2.49 & $0.28-22.50$ & 0.417 \\
\hline Smoking ( $\geq 2$ cigarettes/d) & 1.98 & $0.58-6.82$ & 0.277 \\
\hline Overweight (125 kg/m2) & 1.43 & $0.64-3.18$ & 0.383 \\
\hline Insomnia (AIS score $\geq 8$ ) & 1.13 & $0.58-2.22$ & 0.715 \\
\hline Age, y & 1.04 & $0.94-1.14$ & 0.466 \\
\hline Physical inactivity ( BBO min/d of physical activity) & 0.85 & $0.43-1.68$ & 0.632 \\
\hline
\end{tabular}

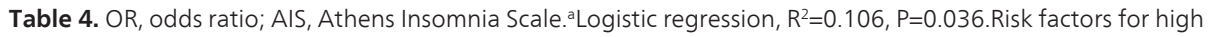
lipoperoxide levels, as oxidative stress biomarker, in perimenopausal women [49].

Unsaturated fatty acids have a role in the pathogenesis of atherosclerosis. They are very sensitive to oxidation caused by excess free oxygen radicals and the consequent oxidative status, and it is well known that lipid and lipoprotein metabolism is markedly altered in postmenopausal women as it was demonstrated by Signorelli who founded that the oxidative stress is involved in the pathophysiology of atherosclerosis. Malonaldehyde (MDA), 4hydroxynenal (4-HNE), oxidized lipoproteins (ox LDL) were higher in postmenopausal while GSH-PX concentrations were significantly higher in fertile women [48]. 
Similar findings were found in pre and postmenopausal Mexican women by Sánchez. Lipoperoxides, erythrocyte superoxide dismutase and glutathione peroxidase activities, the total antioxidant status, pro-oxidant factors, body mass index were evaluated. The lipoperoxide levels were significantly higher in the postmenopausal group than in the premenopausal group, which concluded that menopause is the main risk factor for oxidative stress [49].

However, there are other contrasting studies, in example in a report was found than postmenopausal women had lower levels of lipid hydroperoxide oxidation, the MDA levels did not differ between pre- and postmenopausal women, no differences in advanced oxidation protein products (AOPP) and nitrite levels were observed between pre- and postmenopausal women. Postmenopausal women also exhibited a higher total radical antioxidant level [50].

Another study included pre-menopausal, peri-menopausal, and post-menopausal women classified according to the Staging of Reproductive Aging Workshop (STRAW) criteria. No significant correlations between E2 levels and OS markers were detected and consequently, estrogen decline during menopausal transition is not a determinant factor for oxidative stress [51].

\section{Associated diseases to oxidative stress}

There are several evidences that related to oxidative stress with diseases present in postmenopausal women in example depression, osteoporosis, cardiovascular diseases and leg vasoconstriction.

\section{DEPRESSION}

The depression is the most frequent symptom in postmenopausal women, even is a major cause of medical consultation. This disorder has cerebral implications, as showed post-mortem studies in patients with depressive disorder pointed a significant decrease of neuronal and glial cells in cortico-limbic regions which can be seen as a consequence of alterations in neuronal plasticity. This could be triggered by an increase of free radicals which in its turn eventually leads to cell death and consequently atrophy of vulnerable neuronal and glial cell population in these regions [52]. In addition elevated levels of MDA adversely affected the efficiency of visual-spatial and auditory-verbal working memories; short-term declarative memory and the delayed recall declarative memory were founded. 1 . Higher concentration of plasma MDA in recurrent depressive disorder (rDD) patients is associated with the severity of depressive symptoms 2 . Elevated levels of plasma MDA are related to the impairment of visual-spatial and auditory-verbal working memory and short-term and delayed declarative memory [53]. Actually too is known that estrogen protect neurons against oxidative damage excitotoxins, and beta-amyloid-induced toxicity in cell culture, reduces the serum monoamino oxidase levels and might regulate learning and memory. Nitric oxide (NO) is a messenger and in the central nervous system and acts as neurotransmitter/neuromodulator like serotonin, bradykinin, endothelin, acetylcholine and noradrenaline. Estrogen induces activity of constitutive NO synthase, reduces hyperphosphorylated of Tau and 
stimulates phosphorylated GSK3b [54]; due to in menopause its reduction induces a depressive disorder [55].

\section{OSTEOPOROSIS}

Oxidative stress participates in decreasing bone formation and stimulating bone resorption. Furthermore, antioxidant enzymes have been observed to have low protective activity in women with osteoporosis, also has been determined higher urine deoxypyridinoline, total Peroxide (TPx), MDA, nitric oxide, also lower TAS and glutathione reductase, compared with postmenopausal women whitout osteoporosis [56,57]. Likewise has been studied polymorphism associated with enzymes involved in oxidative balance such as of the glutathione S-reductase (GSR), superoxide dismutase (SOD1 and SOD2), and catalase (CAT), of which polymorphisms from GSR were associated to bone mineral density [58]. Both oxidative stress and associated polymorphisms are useful tool to predict which patients might develop osteoporosis.

\section{CARDIOVASCULAR DISEASES}

Oxidative stress biomarkers have been linked with the presence and severity of the CVD, and to the presence and number of risk factors. It is known that young women during their fertile life are at lower risk of cardiovascular events compared with men, being protected by estrogen action and that oxidative stress is generally higher in men than in premenopausal women. However, after menopause the risk of experiencing cardiovascular events rapidly rises in women, in conjunction with a parallel increase in oxidative stress. Moreover, although oxidative stress results are lower in females compared to males during the first decades of life, this difference decreases until the age range which corresponds to the onset of menopause for women [59].

An analyses of relationship among excess iron, oxidative stress, and centralized fat mass in healthy postmenopausal women showed that almost $14 \%$ of the variability in oxLDL was accounted for by centralized fat mass AndGynFM ratio (waistphip=thigh $1 / 4$ AndGynFM), age, and serum iron. Similarly, $16 \%$ the variability in 15-isoprostane F2 ${ }_{\mathrm{a} \alpha}$ (PGF F2 $2_{\mathrm{a} \alpha}$ ) was accounted for by the AndGynFM ratio, HOMA, and serum iron. Also it was accounted for $33 \%$ of the variability in AndGynFM ratio by high-density lipoprotein cholesterol (HDL-C), ferritin, HOMA, oxLDL, and PGF F2a $\alpha$, all of before suggests that reducing centralized fat mass and maintaining a favorable lipid profile, antioxidant status, and iron status all may be important in protecting postmenopausal women from atherosclerotic CVD [60]. Similar findings has been observed in diabetic postmenopausal women in whom it has been reported higher levels of total cholesterol (TC), triglyceride (TG), low density lipoprotein cholesterol (LDL-C), very low density lipoprotein cholesterol (VLDL-C), catalase (CAT), and malondialdehyde (MDA) and significantly lower levels of HDL-C, reduced glutathione (GSH), glutathione reductase (GR), glutathione peroxidase (GPx), and superoxide dismutase (SOD) [61]. Fact means a cardiovascular risk.

\section{LEG VASOCONSTRICTION}

Leg vasoconstriction has been linked to oxidative stress due to the fact that Intravenous administration of a supraphysiological dose of the antioxidant ascorbic acid increased leg 
blood flow in the postmenopausal women as a result of an increase in leg vascular conductance, but it did not affect leg blood flow in premenopausal controls or mean arterial pressure, also changes in leg blood flow and leg vascular conductance with ascorbic acid were related to high plasma oxidized LDL an low antioxidant status [62] (Table 5, Figure 7).

\begin{tabular}{lll}
\hline Variable & Premenopausal & Postmenopausal \\
\hline Oxidized LDL, U/I & $36.9 \pm 4.9$ & $55.6 \pm 3.3^{*}$ \\
\hline TAS, mmol/l & $1.4 \pm 0.1$ & $1.1 \pm 0.1^{*}$ \\
\hline ACE, $\mathrm{U} / \mathrm{l}$ & $26.2 \pm 3.9$ & $30.3 \pm 2.6$ \\
\hline Endothelin-1, pg/ml & $4.8 \pm 0.5$ & $5.3 \pm 0.3$ \\
\hline Norepinephrine, pg/ml & $149 \pm 39$ & $343 \pm 28^{*}$ \\
\hline Epinephrine, $\mathrm{pg} / \mathrm{ml}$ & $20 \pm 3$ & $27 \pm 2$ \\
\hline
\end{tabular}

Table 5. Values are means $\pm S E, A C E$ angiotensin-converting enzyme. *P团.05 vs premenopausal.Serum biomarkers associated to leg vasoconstriction [62].
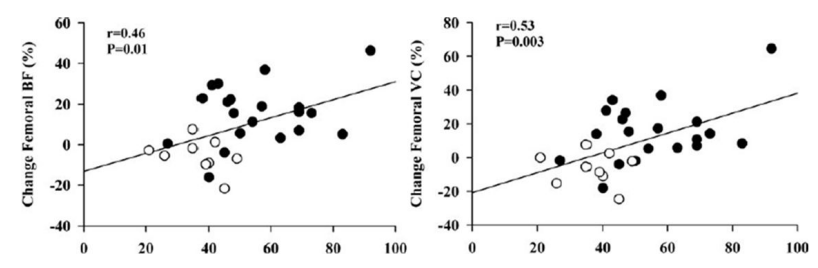

Figure 7. Relationship between plasma oxidized low-density lipoprotein (LDL) and the change in femoral artery BF (top) and vascular conductance VC (bottom) with ascorbic acid in premenopusal ( 可 and postmenopausal (•) women [62].

In addition, long-term studies indicate that total cholesterol (TC), LDL cholesterol (LDL-C), triglycerides (TG), MDA and common carotid artery wall intima-media thickness (IMT) are higher in women with hormonal depletion over 5 years, reveling a close temporal correlation between plasma oxidative and carotid wall IMT as postmenopause proceeds [63].

Further investigations are needed to examine the roll of oxidative stress as an endogenous bioactive agent related to disease in post-menopausal women. Since oxidative stress is the imbalance between total oxidants and antioxidants in the body, any single oxidant/ antioxidant parameter may not reflect oxidative stress. Further studies are needed to understand the underlying mechanisms of before findings.

\section{Hormonal replacement therapy}

Hormone replacement therapy (HRT) is defined as treatment that estrogen provides women to improve the characteristic symptoms of menopause [64], especially osteoporosis, dyslipi- 
demias, mood among others, is also important to note that hormone replacement therapy is not without risks.

There are three Hormonal Replacement Therapies (HRT) treatment regimens:

- 1.- Estrogens. They may be natural or synthetic. Estrogens (17 $\beta$-Estradiol and Estriol) and conjugated equine estrogens, and these are administered orally. Estrogens may administrated by oral, subcutaneous routes, also intravaginal estrogen (tablets, creams, ovules), alone or combined with progestin, are suitable for vaginal symptoms, with no significant increase in endometrial hyperplasia or proliferation.

- 2 - Progestogens. They are administered in combination with estrogen to reduce the risk of endometrial hyperplasia and cancer. Currently most used active ingredients $\mathrm{TH}$ are: oral micronized progesterone, medroxyprogesterone and norethisterone. Progestins are mainly used orally, although there are preparations to be administered in combination with estrogen transdermal route [65].

- 3 - Another group of drugs called STEAR (Selective Tissue Estrogenic Activity Regulator) is widely used because it has tissue-specific metabolism, and a main representative is Tibolone, this is a synthetic steroid with weak estrogenic, androgenic and gestagenic activities, which controls vasomotor symptoms, prevents bone demineralization and improves mood [66]. Tibolone improves vaginal symptoms and no significant differences when compared to estrogen, decreases menopausal symptoms, although moderately increases bone density and inhibit bone resorption. In the cardiovascular system there is no evidence of efficacy for the primary or secondary prevention of diseases associated with menopause at this level [67].

\section{Effects of hormonal replacement therapy on oxidative stress}

As mentioned above, there are different pathologies in the menopause that improve after administrating of hormone replacement therapy, fact that aroused the interest in evaluating their effects on biomarkers of oxidative stress, which has been recognized its participation in illnesses as cancer, atherogenesis, Alzheimer's and aging among others. Below are described the findings on changes in oxidative stress biomarkers after administrating HRT by periods time.

\section{LESS THAN THREE MONTHS}

In African American and Caucasian posmenopausal women the HRT reduced plasma levels of free 8-isoprostane after 6 weeks of HT, at the same time nitrite increased, principally in Caucasian women. Both ethnics groups have reduced levels of oxidative stress but the differences were not statistically significant [68]. Even the combined therapy for 3 months had an antioxidant effect in posmenopausal hemodialysis women, who showed reduced levels of MDA although TAC, uric acid and C- reactive protein were not changed [69].

Oxidized low-density lipoprotein (oxLDL)/ $\beta 2$-glycoprotein I ( $\beta 2 \mathrm{GPI})$ complexes are etiologically important in the development of atherosclerosis. Combined HRT led to a significant 
increase in TAC and a minor but statistically nonsignificant decrease of oxLDL/ $\beta 2$ GPI complexes when compared with the baseline control levels. There was also no significant association between TAC and oxLDL/ß2GPI complexes changes related to HRT. This study indicates that, HRT in postmenopausal women leads to an increase in TAC without an equivalent change in serum levels of oxLDL/ $\beta 2 \mathrm{GPI}$ complexes. It is concluded that beneficial effects of HRT could be explained, at least in part, by improving antioxidant status, but may not be directly associated with a change in oxidized lipoprotein production [70] (Figure 8).
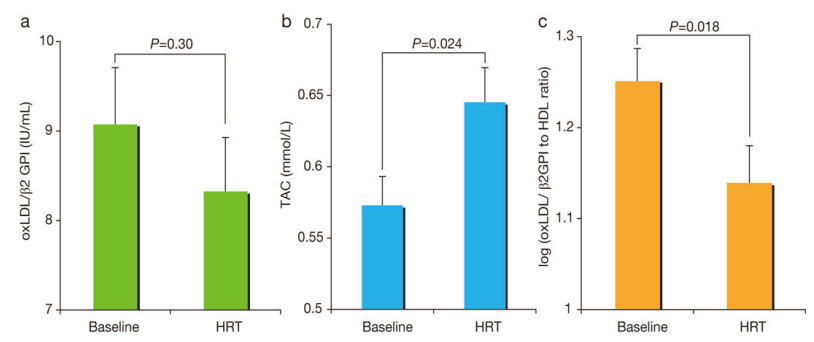

Figure 8. Effects of hormone replacement therapy (HRT) on oxLDL/ $\beta 2$ GPI (a), total antioxidant capacity (TAC) (b), oxLDL/ $\beta 2$ GPI to HDL-C ratio (c) in the studied subjects. Values are means $\pm \mathrm{SE}$. $\mathrm{P}<0.05$ (paired sample t-test). total serum antioxidant capacity (TAC) as ferric reducing ability of plasma (FRAP) and related these to HRT and oxLDL/ $32 \mathrm{GPI}$ complexes level [70].

\section{SIX MONTHS}

The main studies about effect of HRT has been carried out with combination estrogen plus gestagen, and in them has been founded in example that carbonils groups determined by ELISA showed a reduction of serum levels after six months oral or transdermal treat when compared with control group, and there was not difference between oral and transdermal, which indicates that hormonal therapy reduces the of carbonyl protein, a marker of oxidative stress, suggesting potential protective effect [71]. Similar result were founded with the serum level of malondialdehyde, superoxide dismutase and sulfhydryl groups without changes on plasma total homocysteine (tHcy) (used as atherogenic indicator) [72]. Another study with equal number of months of follow-up showed that carbonyls, MDA and oxLDL were reduced, while erythrocyte glutathione (GSH) were increased, and nitrotyrosine (NT) levels were not changed $[73,74]$ (Table 6).

On the other hand Tibolone treatment leads to a decrease in concentrations of plasma lipid peroxide, increase plasma concentrations of vitamin $\mathrm{E}$ and alpha-tocopherol and significant decrease in lipid peroxide concentrations [75, 76].

\section{ONE YEAR}

However, the combined treatment by one year significantly reduced the levels of catecholamines, mean blood pressure and LDL cholesterol while it increased levels of nitrite/nitrate, indicating cardiovascular benefit in healthy recent postmenopausal women. Levels of 8-epi PGF2alpha did not change, suggesting no evident relationship between HRT and oxidative 
stress [77]. Although another study reports that conjugated estrogens alone (EHRT) or conjugated estrogen with medroxyprogesterone acetate can reduce lipoprotein lipase (LPL), hepatic lipase (HL), oxidized apolipoprotein B in LDL [78] also platelet MDA, glutathione-Stransferase (GST) and SOD levels were lower and total thiol (t-SH) content was higher than pre-treatment levels. These results indicate that hormone replacement therapy may affect platelet membrane fatty acid content and oxidant-antioxidant balance in postmenopausal women [79].

\begin{tabular}{llll}
\hline & MPA $\mathbf{n = 2 5}$ & NETA $\mathbf{n = 2 0}$ & Total $\mathbf{n = 4 5}$ \\
\hline Total-C & $204.1 \pm 30.0 /$ & $225.7 \pm 30.1 /$ & $213.7 \pm 31.7 /$ \\
Pre/postreatment $(\mathrm{mg} / \mathbf{1 0 0 m l})$ & $178.6 \pm 10.7^{*}$ & $191.6 \pm 21.1^{*}$ & $184.4 \pm 17.2^{*}$ \\
\hline HDL-C & $45.7 \pm 10.6 /$ & $49.1 \pm 11.0 /$ & $47.2 \pm 10.8 /$ \\
Pre/postreatment $(\mathrm{mg} / \mathbf{1 0 0 m l})$ & $53.2 \pm 7.6^{*}$ & $56.6 \pm 8.2$ & $54.8 \pm 8.0^{*}$ \\
\hline LDL-C & $131.7 \pm 24.9 /$ & $147.5 \pm 25.2 /$ & $138.71 \pm 26.08 /$ \\
Pre/postreatment $(\mathrm{mg} / 100 \mathrm{ml})$ & $102.8 \pm 13.6^{*}$ & $112.7 \pm 21.2^{*}$ & $107.2 \pm 17.9^{*}$ \\
\hline Triglycerides & $133.5 \pm 62.0 /$ & $138.4 \pm 74.4 /$ & $135.67 \pm 67.1 /$ \\
Pre/postreatment $(\mathrm{mg} / 100 \mathrm{ml})$ & $115.2 \pm 35.2$ & $113.5 \pm 37.0$ & $114.4 \pm 35.6$ \\
\hline MDA & $4.7 \pm 0.4 /$ & $4.9 \pm 0.4 /$ & $4.82 \pm 0.4 /$ \\
Pre/postreatment $(\mathrm{mg} / \mathbf{1 0 0 m l})$ & $4.0 \pm 0.4^{*}$ & $3.6 \pm 0.3^{*}$ & $3.8 \pm 0.4^{*}$ \\
\hline OxLDL & $54.9 \pm 8.5 /$ & $53.1 \pm 8.3 /$ & $54.13 \pm 8.34 /$ \\
Pre/postreatment $(\mathrm{mg} / \mathbf{1 0 0 m l})$ & $47.9 \pm 4.0^{*}$ & $44.8 \pm 4.4^{*}$ & $46.6 \pm 4.4^{*}$ \\
\hline PON 1 & $51.5 \pm 6.7 /$ & $51.4 \pm 9.0 /$ & $51.47 \pm 7.7 /$ \\
Pre/postreatment $(\mathrm{mg} / \mathbf{1 0 0 m l})$ & $73.9 \pm 11.2^{*}$ & $67.4 \pm 10,0^{*}$ & $71.0 \pm 11.1^{*}$ \\
\hline
\end{tabular}

Table 6. Comparinson of parameters before and after HRT in postmenopausal women p 0.005 Serum lipid parameters, MDA, oxLDL and PON1 levels in postmenopausal women before and after HRT [74].

Similarly the effect of DNA damage by oxidative stress has been evaluated. The 8-hydroxydeoxyguanosine (8-OHdG) is widely used for determination of DNA damage since it is excised from oxidative damaged DNA with endonuclease repair enzymes coded (OGG1). After HT, mean blood 8-OHdG (DNA damage marker) level significantly decreased compared to those before HT, while urinary 8-OHdG level did not show any difference, this without relation with S326C polymorphism [80].

Tibolone acts as an antioxidant upon increase the concentration of reduced sulfhydryl [81], however, the exact mechanism has not been elucidated, but it could participate in a direct mechanism, ie through the structure tibolone and its metabolites as it is similar to the structure of $17 \beta$-estradiol, considered as an antioxidant for its phenol ring, which can act neutralizing to free radical [82, 83]. Moreover tibolone reduces the concentration of malondialdehyde compared to those who had no treatment $[84,85]$. 
Although there are reports that indicate the antioxidant effect of HRT, there are also studies that indicate otherwise; in example in another study combined HRT led to decreased plasma total and LDL cholesterol, but did not affect oxidizability and oxidation of LDL. Circulating levels of antioxidant vitamins (beta-carotene, vitamin C, vitamin E/triglycerides) and total antioxidant capacity of plasma and lipid peroxidation, assessed by plasma TBARs, were not different from controls in postmenopausal women receiving HRT, which indicates that combined HRT modifies the blood lipid profile, however it does not appear to influence oxidative status [86]. Additionaly DNA damage, GPx activity and nitrite level as well as a decreased GSH level were observed after oral administrating of estrogens alone or combinated [87].

With respect to hot flushes, they have been associated to smaller level of total antioxidant activity in plasma, without differences in nitrite-nitrate concentrations, and after HRT there is an increase in total antioxidant activity level and nitrite-nitrate concentrations in menopausal women, with and without hot flushes [88].

On the other side estrogen increases vasodilatation and inhibits the response of blood vessels to injury and the development of atherosclerosis, it has been related to hormone's effect on serum lipid concentration, that is reducing MDA and oxLDL levels and increasing activity of paroxonase PON1, which a calcium-dependent enzyme and in serum is exclusively located on HDL. PON is synthesized and secreted by liver and tightly binds to HDL subfractions that also contain apoA-1 and apoJ or clusterin and it has the capacity to protect LDL against oxidation $[89,90,91]$.

\section{Effect of nutrition and exercise on oxidative stress biomarkers}

Adequate nutrition and physical exercise are two factors of health promotion and its effect on oxidative stress has been investigated in postmenopausal women, which has given controversial data. With respect to foods, they contain large amount of antioxidant molecules from there arouse the interest to check if their use can reduce the oxidative stress observed in postmenopause.

For example it was reported that the intake of fresh, greenhouse-grown vegetables for 3-wk did not induced changes in the urine concentrations of 8 -isoprostane F2 $\alpha$, hexanoyl lysine, and serum high sensitivity C-reactive protein despite that plasma carotenoids were elevated in overweight postmenopausal women [92]. Something similar was established with a 2month supplementation period with the Klamath algae extract, which is an extract naturally rich in powerful algal antioxidant molecules (AFA-phycocyanins) and concentrated with Klamath algae's natural neuromodulators (phenylethylamine as well as natural selective MAO-B inhibitors), whose effect was to increase in the plasma levels of carotenoids, tocopherols and retinol, however in this study oxidative stress was not measured [93, 94].

Otherwise is soy milk consumption for four weeks, which did not reduced markers of inflammation and oxidative stress as (tumor necrosis factor alpha [TNF-alpha], interleukin 
[IL]-1beta, IL-6) and oxidative stress (superoxide dismutase [SOD], glutathione peroxidase [GPx], cyclooxygenase-2 [COX-2]) [95]. In this sense has also been found that de-alcoholised wine (DAW) with different polyphenol content by one month does not exert a protective activity towards oxidative DNA damage by comet assay, nor modifies significantly the gene expression profile of peripheral lymphocytes, whereas it shows blood-fluidifying actions, expressed as a significant decrease in blood viscosity. However, this effect does not correlate with the dosage of polyphenols from (DAW) [96].

In contrast, the intake for 8 weeks of soya protein diet and soya nut diet decreased MDA and increased the total antioxidant capacity in postmenopausal women with metabolic syndrome [97]. Extra-virgin olive oils (EVOO) is another example of food which reduces DNA damage by oxidative stress when is administrated for 8 weeks in healthy postmenopausal, which was evaluated by the comet assay in peripheral blood lymphocytes [98].

Nevertheless there are also reports of foods that raise oxidative stress as with American ginseng (AG) and wine. The AG supplementation at $500 \mathrm{mg}$ every day for 4 months causes oxidative stress in postmenopausal women, due to reduced total antioxidant capacity, elevated plasma malondialdehyde and urine 8-hydroxydeoxyguanosine concentrations and increased erythrocyte antioxidant enzyme activity such as erythrocyte superoxide dismutase and GSH reductase [99].

Previous studies do not allow a conclusion on the effect of foods rich in antioxidant compounds, because were used different markers and administration time, and still more the age range of the postmenopausal differs considerably. This shows the need for more studies. Before shows the importance of further research with other foods with antioxidant properties known such as:

Vitamin C - Citrus fruits and their juices, berries, dark green vegetables (spinach, asparagus, green peppers, brussel sprouts, broccoli, watercress, other greens), red and yellow peppers, tomatoes and tomato juice, pineapple, cantaloupe, mangos, papaya and guava.

Vitamin E - Vegetable oils such as olive, soybean, corn, cottonseed and safflower, nuts and nut butters, seeds, whole grains, wheat, wheat germ, brown rice, oatmeal, soybeans, sweet potatoes, legumes (beans, lentils, split peas) and dark leafy green vegetables. Selenium - Brazil nuts, brewer's yeast, oatmeal, brown rice, chicken, eggs, dairy products, garlic, molasses, onions, salmon, seafood, tuna, wheat germ, whole grains and most vegetables.

Beta Carotene - Variety of dark orange, red, yellow and green vegetables and fruits such as broccoli, kale, spinach, sweet potatoes, carrots, red and yellow peppers, apricots, cantaloupe and mangos [100].

With respect to the lycopene, the following mechanism of the role of lycopene in chronic diseases has been mentioned by Agarwal and Rao [101] and Waliszewski and Blasco [102].

This highlights the importance of promote healthy lifestyles (balanced diet and moderate intensity exercise) in vulnerable populations, such as menopausal women, in order to prevent aging induced oxidative stress-related diseases. 
Whit respect to the exercise has been reported that who practice yoga or tai chi (TC) for a year have same BMI, and even more no effects were shown on erythrocyte superoxide dismutase activity, plasma lipid peroxidation (TBARS) or total homocysteine concentrations, but the activity of erythrocyte glutathione peroxidase - an aerobic training-responsive enzyme - was higher in TC practitioners [103]. Although short term aerobic physical activity program (8 or 15 weeks) exhibited similar results, namely a reduction of serum glucose, LDL-cholesterol (LDL-C), plasma TBARS concentrations, decreasing of HOMA(IR) as well as an increased of total antioxidant status (TAS) of plasma and reduced glutathione (GSH) concentrations in red blood cells (RBC) increased significantly [104, 105].

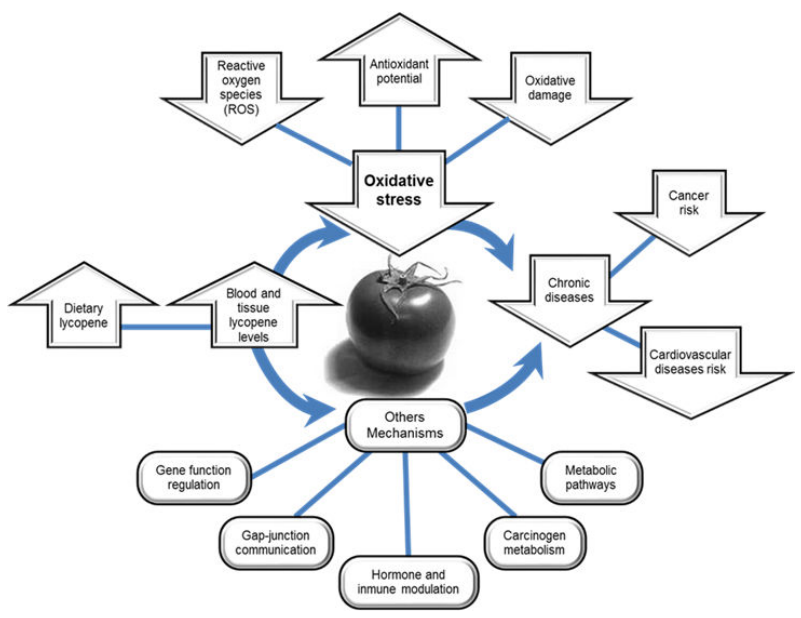

Figure 9. Lycopene and its mechanism in preventing of chronic diseases (Adapted from 101 and 102).

Regular physical training has been shown to upregulate antioxidant enzymatic systems, which may slow down the usual increase of oxidative stress in postmenopausal women, since it has been identified significant negative associations between oxidative stress and indices of physical fitness-activity (malondialdehyde, 8-iso-prostaglandin F2alpha, 8-hydroxy-2'-deoxyguanosine). Conversely, glutathione peroxidase is positively correlated with fitness level, furthermore mean arterial blood pressure (MABP) and cerebrovascular conductance $(\mathrm{CVC})$ are directly associated with 8-hydroxy-2'-deoxyguanosine, nitrotyrosine and nitric oxide (NO) These findings demonstrate that, after menopause, fitness level and regular physical activity mediate against oxidative stress by maintaining antioxidant enzyme efficiency. Furthermore, these results suggest that oxidative stress and NO production modulate MABP and CVC [106].

Contrary to the above has also been reported, that the exercise does not modify the antioxidant status (although this is lower in metabolic healthy obese postmenopausal women than non-metabolic healthy obese postmenopausal women) and worse increases serum levels of thiobarbituric acid-reactive substances [107]. 
This highlights the importance of promote healthy lifestyles (balanced diet and moderate intensity exercise) in vulnerable populations, such as menopausal women, in order to prevent aging induced oxidative stress-related diseases.

\section{Conclusion}

The studies presented here were performed with different number of patients, methodologies and biomarkers, but most of them indicate that estrogen depletion induces oxidative stress and hormone replacement therapy seems to reduce it. With respect to the modification of biomarkers of oxidative stress damage by food and exercise needs more research because so far no conclusive data have been obtained.

\section{Author details}

Claudia Camelia Calzada Mendoza ${ }^{1^{*}}$ and Carlos Alberto Jiménez Zamarripa²

*Address all correspondence to: cccalzadam@yahoo.com.mx

1 Section of Post graduate Studies and Research of Escuela Superior de Medicina- Instituto Politécnico Nacional. Street Salvador Díaz Mirón S/N, Colony Casco de Santo Tomás, Delegation Miguel Hidalgo, C.P. 11340, México D.F.

2 Hospital psychiatry "Dr. Samuel Ramírez Moreno"-psychiatric careservices- Secretaria de Salud, highway México-Puebla Km 5.5, Colony Santa Catarina, Tláhuac, C.P. 13100, México D.F.

\section{References}

[1] Reddish, S. (2011). Menopausal transition- assessment in general practice. Australian Family Physician, 40(5), 266-72.

[2] Burger, H. G., Hale, G. E., Robertson, D. M., \& Dennerstein, L. (2007). Review of hormonal changes during the menopausal transition: focus on findings from the Melbourne Women's Midlife Health Project. Human Reproduction Update, 13(6), 559-65.

[3] de Cetina, Canto T. (2006). Los síntomas en la menopausia. Revista de Endocrinología y Nutrición, 14(3), 141-148.

[4] Guthrie, J. R., Dennerstein, L., Hopper, J. L., \& Burger, H. G. (1996). Hot flushes, menstrual status and hormone levels in a population-based sample of midlife women. Obstetrics and Gynecology, 88, 437-441. 
[5] Zárate, A., Hernández-Valencia, M., Austria, E., Saucedo, R., \& Hernánde, M. (2011). Diagnosis of premature menopause measuring circulating anti-Müllerian hormone. Ginecologia Obstetricia Mexicana, 79(5), 303-7.

[6] Lockwood, C.J. (2011). Mechanisms of normal and abnormal endometrial bleeding. Menopause, 18(4), 408-411.

[7] Goldstein, S.R. (2011). Significance of incidentally thick endometrial echo on transvaginal ultrasound in postmenopausal women. Menopause, 18(4), 434-436.

[8] Chapple, C. R., Wein, A. J., Abrams, P., Dmochowski, R. R., Giuliano, F., Kaplan, S. A., Mc Vary, K. T., \& Roehrborn, C. G. (2008). Lower urinary tract symptoms revisited: a broader clinical perspective. European Urology, 54(3), 563-569.

[9] Labrie, F., Archer, D., Bouchard, C., Fortier, M., Cusan, L., Gomez, J. L., Girard, G., Baron, M., Ayotte, N., Moreau, M., Dubé, R., Côté, I., Labrie, C., Lavoie, L., Berger, L., Gilbert, L., Martel, C., \& Balser, J. (2009). Intravaginaldehydroepiandrosterone (Prasterone), a physiological and highly efficient treatment of vaginal atrophy. Menopause, 16(5), 907-22.

[10] Goepel, M., Kirschner-Hermanns, R., Welz-Barth, A., Steinwachs, K. C., \& Rübben, H. (2010). Urinary incontinence in the elderly: part 3 of a series of articles on incontinence. Dtsch Arzteblint, 107(30), 531-6.

[11] Morrison, L. A., Sievert, L. L., Brown, D. E., Rahberg, N., \& Reza, A. (2010). Relationships between menstrual and menopausal attitudes and associated demographic and health characteristics: the Hilo Women's Health Study Women Health,, 50(5), 397-413.

[12] Pachman, D. R., Jones, J. M., \& Loprinzi, C. L. (2010). Management of menopauseassociated vasomotor symptoms: Current treatment options, challenges and future directions. International Journal Womens Health, 9(2), 231-35.

[13] Archer, D. F., Sturdee, D. W., Baber, R., de Villiers, T. J., Pines, A., Freedman, R. R., Gompel, A., Hickey, M., Hunter, M. S., Lobo, R. A., Lumsden, M. A., Mac, Lennan. A. H., Maki, P., Palacios, S., Shah, D., Villaseca, P., \& Warren, M. (2011). Menopausal hot flushes and night sweats: where are we now ? Climacteric, 14(5), 155-128.

[14] Frutos, R., Rodríguez, S., Miralles-Jorda, L., \& Machuca, G. (2002). Oral manifestations and dental treatment in menopause. Medicine Oral, 7(1), 26-30.

[15] Safoury, O., Rashid, L., \& Ibrahim, M. A. (2010). Study of androgen and estrogen receptors alpha, beta in skin tags. Indian Journal Dermatology, 55(1), 20-4.

[16] Maltais, M.L., Desroches, J., \& Dionne, I.J. (2009). Changes in muscle mass and strength after menopause. Journal Musculo skeletand Neuronal Interactions, 9(4), 186-197.

[17] Sosa, M., Saavedra, P., Jódar, E., Lozano, T. C., Quesada, J. M., Torrijos, A., Pérez, C. R., Nogués, X., Díaz, C. M., Moro, M. J., Gómez, C., Mosquera, J., Alegre, J., Olmos, J., 
Muñoz, T. M., Guañabens, N., Del Pino, J., \& Hawkins, F. (2009). Bone mineral density and risk of fractures in aging, obese post-menopausal women with type 2 diabetes. The GIUMO Study. Aging Clinical Experimental Research, 21(1), 27-32.

[18] Koroglu, B. K., Kiris, F., Ersoy, I. H., Sutcu, R., Yildiz, M., Aksu, O., Ermis, F., Ersoy, S., \& Tamer, M. N. (2011). Relation of leptin, adiponectin and insulin resistance to bone mineral density in type 2 diabetic postmenopausal women. Endokrynologia Polska, 62(5), 429-35.

[19] Nelson, H. D., Helfand, M., Woolf, S. H., \& Allan, J. D. (2002). Screening for Postmenopausal Osteoporosis: A Review of the Evidence for the U.S. Preventive Services Task Force. Annals of Internal Medicine, 137(6), 529-41.

[20] del Rio, B. L., Romera, B. M., Pavia, S. J., Setoain, Q. J., Serra, M. L., Garces, R. P., \& Lafuente, N. C. (1992). Bone mineral density in two different socio-economic population groups. Bone and Mineral, 18(2), 159-68.

[21] Suresh, S., Kumar, T. S., Saraswathy, P. K., \& Pani, S. K. H. (2010). Periodontitis and bone mineral density among pre and post menopausal women: A comparative study. Journal of Indian Society of Periodontology, 14(1), 30-34.

[22] Pavón, P., Alameda, H. C., \& Olivar, R. J. (2006). Obesidad y menopausia. Nutrición Hospitalaria, 21, 633-637.

[23] Zillikens, M. C., Uitterlinden, A. G., van Leeuwen, J. P., Berends, A. L., Henneman, P., van Dijk, K. W., Oostra, B. A., van Duijn, C. M., Pols, H. A., \& Rivadeneira, F. (2010). The role of body mass index, insulin, and adiponectin in the relation between fat distribution and bone mineral density. Calcified Tissue International, 86(2), 116-25.

[24] Cho, E. J., Min, Y. J., Oh, M. S., Kwon, J. E., Kim, J. E., Lee, W. S., Lee, K. J., Kim, S. W., Kim, T. H., Kim, M. A., Kim, C. J., \& Ryu, W. S. (2011). Effects of the transition from premenopause to postmenopause on lipids and lipoproteins: quantification and related parameters. Korean Journal Internal Medicine, 26(1), 47-53.

[25] Kallikazaros, I., Tsioufis, C., Zambaras, P., Skiadas, I., Toutouza, M., Tousoulis, D., Stefanadis, C., \& Toutouzas, P. (2008). Estrogen-induced improvement in coronary flow responses during atrial pacing in relation to endothelin-1 levels in postmenopausal women without coronary disease. Vascular Health Risk and Management, 4(3), 705-14.

[26] Zavala, A. G., \& Grover, F. (2007). Perfil lipídico y cambio en sensibilidad a la insulina en posmenopáusicas. Revista Médica deChile 135:, 613-619.

[27] Garay, S., \& Arellano, S. (2006). Diabetes mellitus (DM), menopausia y reemplazo hormonal. Revista de Endocrinología y Nutrición, 14(3), 191-195.

[28] Whitcroft, S., \& Herriot, A. (2011). Insulin resistance and management of the menopause: a clinical hypothesis in practice. Menopause International, 17(1), 24-8. 
[29] Ryan, J., Scali, J., Carrière, I., Peres, K., Rouaud, O., Scarabin, P. Y., Ritchie, K., \& Ancelin, M. L. (2011). Estrogen receptor alpha gene variants and major depressive episodes. Jornal of Affective Disorders, 136(3), 1222-6.

[30] Parry, B.L. (2010). Optimal management of perimenopausal depression. International Joornal of Women's Health, 9(2), 143-151.

[31] Zender, R., \& Olshansky, E. (2009). Women's mental health: depression and anxiety. The Nursing Clinics of North America, 44(3), 250-256.

[32] Colangelo, L. A., Craft, L. L., Ouyang, P., Liu, K., Schreiner, P. J., Michos, E. D., \& Gapstur, S. M. (2012). Association of sex hormones and sex hormone-binding globulin with depressive symptoms in postmenopausal women: the Multiethnic Study of Atherosclerosis. Menopause. Mar 12.PMID: 22415566 [PubMed- as supplied by publisher] PMCID: PMC3376685.

[33] Escalante, G. C., Quesada, M. S., \& Zeledón, S. F. (2009). Oxidative Profile of the Menopausal Woman: Estrogens' Rol in the Prevention and Treatment of Diseases. Acta Médica Costarricense, 51(4), 206-2011.

[34] Ghosh, D., Griswold, J., Erman, M., \& Pangborn, W. (2009). Structural basis for androgen specificity and oestrogen synthesis in human aromatase. Nature, 457(7226), 219-223.

[35] Liehr J.G. (2000). Is Estradiol a Genotoxic Mutagenic Carcinogen?. Endocrine Reviews, 21(1), 40-54.

[36] Lippert, T. H., Seeger, H., \& Mueck, A. O. (2000). The impact of endogenous estradiol metabolites on carcinogenesis. Steroids, 65, 357-369.

[37] Pulvirenti, D., Signorelli, S., Sciacchitano, S., Di Pino, L., Tsami, A., Ignaccolo, L., \& Neri, S. (2007). Hyperhomocysteinemia, oxidative stress, endothelial dysfunction in postmenopausal women. La Clinica Terapeutica, 158(3), 213-7.

[38] Nascimento, G. R., Barros, Y. V., Wells, A. K., \& Khalil, R. A. (2009). Research into Specific Modulators of Vascular Sex Hormone Receptors in the Management of Postmenopausal Cardiovascular Disease. Current Hypertension Reviews, 5(4), 283-306.

[39] Ratiani, L., Parkosadze, G., Cheishvili, M., Ormotsadze, G., Sulakvelidze, M., \& Sanikidze, T. (2012). Role of estrogens in pathogenesis of age-related disease in women of menopausal age. Georgian Medical News, 203, 11-6.

[40] Liu, S. B., Han, J., Zhang, N., Tian, Z., Li, X. B., \& Zhao, M. G. (2011). Neuroprotective effects of oestrogen against oxidative toxicity through activation of G-protein-coupled receptor 30 receptor. Clinical and Experimental Pharmacology and Physiology, 38(9), 577-85.

[41] Johnson, D. K., Mc Millin, G. A., Bishop, M. L., Fody, E. P., \& Schoeff, L. E. (2010). Enzymes. In: Clinical Chemistry Techniques, Principles, Correlations 6th ed. Philadelphia: Lippincott Williams and Wilkins., 300. 
[42] Vasudevan, D. M., \& Sreekumari, S. (2005). Iso-enzymes and clinical enzymology. In: Vasudevan DM, Sreekumari S, editors. Textbook of Biochemistry (for medical students). 4th ed. New Delhi: Jaypeebrothers medical publishers (P) Ltd., 57.

[43] Abdul, R. O. F., Al, S. G. A., \& Bushra, H. Z. B. H. (2010). Serum $\gamma$-glutamyltransferase as Oxidative Stress Marker in Pre-and Postmenopausal Iraqi Women. Oman Medical Journal, 25(4), 286-8.

[44] Zitňanová, I., Rakovan, M., Paduchová, Z., Dvořáková, M., Andrezálová, L., Muchová, J., Simko, M., Waczulíková, I., \& Duračková, Z. (2011). Menopause Oxidative stress in women with perimenopausal symptoms. Menopause, 18(11), 1249-55.

[45] Mittal, P. C., \& Kant, R. (2009). Correlation of increased oxidative stress to body weight in disease-free post menopausal women. Clinical Biochemistry 42(10-11) 1007-11.

[46] Pansini, F., Cervellati, C., Guariento, A., Stacchini, M. A., Castaldini, C., Bernardi, A., Pascale, G., Bonaccorsi, G., Patella, A., Bagni, B., Mollica, G., \& Bergamini, C. M. (2008). Oxidative stress, body fat composition, and endocrine status in pre- and postmenopausal women. Menopause, 15(1), 112-8.

[47] Baltacioğlu, E., Akalin, F. A., Alver, A., Balaban, F., Unsal, M., \& Karabulut, E. (2006). Total antioxidant capacity and superoxide dismutase activity levels in serum and gingival crevicular fluid in post-menopausal women with chronic periodontitis. Journal of Clininal Periodontology, 33(6), 385-92.

[48] Signorelli, S. S., Neri, S., Sciacchitano, S., Pino, L. D., Costa, M. P., Marchese, G., Celotta, G., Cassibba, N., Pennisi, G., \& Caschetto, S. (2006). Behaviour of some indicators of oxidative stress in postmenopausal and fertile women. Maturitas, 53(1), 77-82.

[49] Sánchez, R.M.A., Zacarías, F.M., Arronte, R.A., Correa, M.E., \& Mendoza, Núñez V.M. (2012). Menopause as risk factor for oxidative stress. Menopause, 19(3), 361-7.

[50] Victorino, V. J., Panis, C., Campos, F. C., Cayres, R. C., Colado-Simão, A. N., Oliveira, S. R., Herrera, A. C., Cecchini, A. L., \& Cecchini, R. (2012). Decreased oxidant profile and increased antioxidant capacity in naturally postmenopausal women. Studio controversial. Age (Dordrecht Netherlands) May 28. PMID: 22645022.

[51] Cervellati, C., Pansini, F. S., Bonaccorsi, G., Bergamini, C. M., Patella, A., Casali, F., Fantini, G. F., Pascale, G., Castaldini, C., Ferrazzini, S., Ridolfi, F., Cervellati, G., Cremonini, E., Christodoulou, P., \& Bagni, B. (2011). Estradiol levels and oxidative balance in a population of pre-, peri-, and post-menopausal women. Gynecological Endocrinology, 27(12), 1028-32.

[52] Michel, T. M., Pülschen, D., \& Thome, J. (2012). The role of oxidative stress in depressive disorder. Current Pharmaceutical Design Jun 6 PMID: 22681168.

[53] Talarowska, M., Gałecki, P., Maes, M., Bobińska, K., \& Kowalczyk, E. (2012). Total antioxidant status correlates with cognitive impairment in patients with recurrent depressive disorder. Neurochemical Research, 37(8), 1761-7. 
[54] Pinto, A. R., Calzada, M. C. C., Campos, L. M. G., \& Guerra, A. C. (2012). Effect of Chronic Administration of Estradiol, Progesterone, and Tibolone on the Expression and Phosphorylation of Glycogen Synthase Kinase-3b and the Microtubule-Associated Protein Tau in the Hippocampus and Cerebellum of Female Rat. Journal of Neuroscience Research, 90, 878-886.

[55] Wagner, J. A., Tennen, H., Finan, P. H., White, W. B., Burg, M. M., \& Ghuman, N. (2011). Lifetime History of Depression, Type 2 Diabetes, and Endothelial Reactivity to Acute Stress in Postmenopausal Women. International Jornal of Behavioral Medicine Oct 2. PMID: 21964983.

[56] Yilmaz, N., \& Eren, E. (2009). Homocysteine oxidative stress and relation to bone mineral density in post-menopausal osteoporosis. Aging Clinical and Experimental Research 21(4-5)353-7.

[57] Sendur, O. F., Turan, Y., Tastaban, E., \& Serter, M. (2009). Antioxidant status in patients with osteoporosis: a controlled study. Joint Bone Spine, 76(5), 514-8.

[58] Mlakar, S. J., Osredkar, J., Prezelj, J., \& Marc, J. (2012). Antioxidant enzymes GSR, SOD1, SOD2, and CAT gene variants and bone mineral density values in postmenopausal women: a genetic association analysis. Menopause, 19(3), 368-76.

[59] Vassalle, C., Mercuri, A., \& Maffei, S. (2009). Oxidative status and cardiovascular risk in women: Keeping pink at heart. World Journal of Cardiology, 1(1), 26-30.

[60] Crist, B. L., Alekel, D. L., Ritland, L. M., Hanson, L. N., Genschel, U., \& Reddy, M. B. (2009). Association of oxidative stress, iron, and centralized fat mass in healthy postmenopausal women. Journal Women's Health (Larchmt), 18(6), 795-801.

[61] Kumawat, M., Sharma, T. K., Singh, N., Ghalaut, V. S., Vardey, S. K., Sinha, M., \& Kaushik, G. G. (2012). Study of changes in antioxidant enzymes status in diabetic post menopausal group of women suffering from cardiovascular complications. Clinical Laboratory58(3-4) 203-7.

[62] Moreau, K. L., De Paulis, A. R., Gavin, K. M., \& Seals, D. R. (2007). Oxidative stress contributes to chronic leg vasoconstriction in estrogen-deficient postmenopausal women. Journal of Applied Physiology, 102, 890-895.

[63] Signorelli, S. S., Neri, S., Sciacchitano, S., Di Pino, L., Costa, M. P., Pennisi, G., Ierna, D., \& Caschetto, S. (2001). Duration of menopause and behavior of malondialdehyde, lipids, lipoproteins and carotid wall artery intima-media thickness. Maturitas, 39(1), 39-42.

[64] Smith, C. C., Vedder, L. C., Nelson, A. R., Bredemann, T. M., \& Mc Mahon, L. L. (2010). Duration of estrogen deprivation, not chronological age, prevents estrogen's ability to enhance hippocampal synaptic physiology. Proceedings of National Academy of Science of United States of America, 107(45), 19543-19548. 
[65] Griffiths, F., \& Convery, B. (1995). Women's use of hormone replacement therapy for relief of menopausal symptoms, for prevention of osteoporosis, and after hysterectomy. British Journal of General Practice, 45(396), 355-358.

[66] Modelska, K., \& Cummings, S. (2002). Tibolone for postmenopausal women: systematic review of randomized trials. The Journal of Clinical Endocrinology and Metabolism, 87(1), 16-23.

[67] Huang, K. E., \& Baber, R. (2010). Updated clinical recommendations for the use of tibolone in Asian women Climateric,13:, 317-327.

[68] Ke, R. W., Todd, Pace. D., \& Ahokas, R. A. (2003). Effect of short-term hormone therapy on oxidative stress and endothelial function in African American and Caucasian postmenopausal women. Fertiland Steril, 79(5), 1118-22.

[69] Chang, S. P., Yang, W. S., Lee, S. K., Min, W. K., Park, J. S., \& Kim, S. B. (2003). Effects of hormonal replacement therapy on oxidative stress and total antioxidant capacity in postmenopausal hemodialysis patients. Renal Failure 2002, 24(1), 49-57.

[70] Darabi, M., Ani, M., Movahedian, A., Zarean, E., Panjehpour, M., \& Rabbani, M. (2010). Effect of hormone replacement therapy on total serum anti-oxidant potential and oxidized LDL/B2-glycoprotein I complexes in postmenopausal women. Endocrine Journal, 57(12), 1029-1034.

[71] Polac, I., Borowiecka, M., Wilamowska, A., \& Nowak, P. (2011). Oxidative stress measured by carbonyl groups level in postmenopausal women after oral and transdermal hormone therapy. Journal ofObstetric andGynaecology Research 2012 Apr 30. doi:j. , 1447-0756.

[72] Gökkuşu, C., Özbek, Z., \& Tata, G. (2012). Hormone replacement therapy: relation to homocysteine and prooxidant-antioxidant status in healthy postmenopausal women Archives of Gynecology and Obstetretics,, 285(3), 733-9.

[73] Telci, A., Cakatay, U., Akhan, S. E., Bilgin, M. E., Turfanda, A., \& Sivas, A. (2002). Postmenopausal hormone replacement therapy use decreases oxidative protein damage. Gynecolicand Obstetric Investigation, 54(2), 88-93.

[74] Topçuoølu, A., Uzun, H., Aydin, S., Kahraman, N., Vehid, S., Zeybek, G., \& Topçuo@lu, D. (2005). The Effect of Hormone Replaceent Therapy on Oxidized Low Density Lipoprotein Levels and Paroxonase Activity in Postmenopausal women. Tohoku Journal of Experimental Medicine, 205(1), 79-86.

[75] Vural, P., Akgül, C., \& Canbaz, M. (2005). Effects of menopause and tibolone on antioxidants in postmenopausal women. Annals of Clinical Biochemistry, 42(3), 220-3.

[76] Bednarek, T. G., Tworowska, U., Jedrychowska, I., Radomska, B., Tupikowski, K., Bidzinska, S. B., \& Milewicz, A. (2006). Effects of oestradiol and oestroprogestin on erythrocyte antioxidative enzyme system activity in postmenopausal women. ClinicalEndocrinolology (Oxf), 64(4), 463-8. 
[77] Maffei, S., Mercuri, A., Prontera, C., Zucchelli, G. C., \& Vassalle, C. (2006). Vasoactive biomarkers and oxidative stress in healthy recently postmenopausal women treated with hormone replacement therapy. Climacteric $x, 9(6), 452-8$.

[78] Castanho, V. S., Gidlund, M., Nakamura, R., \& de Faria, E. C. (2011). Post-menopausal hormone therapy reduces autoantibodies to oxidized apolipoprotein B100. Gynecological Endocrinology, 27(10), 800-6.

[79] Gökkuşu, C., Tata, G., Ademoğlu, E., \& Tamer, S. (2010). The benefits of hormone replacement therapy on plasma and platelet antioxidant status and fatty acid composition in healthy postmenopausal women. Platelets, 21(6), 439-44, PMID: 20459351.

[80] Kim, H., Ku, S. Y., Kang, J. W., Kim, H., Kim, Y. D., Kim, S. H., Choi, Y. M., Kim, J. G., \& Moon, S. Y. (2011). The 8-hydroxydeoxyguanosine concentrations according to hormone therapy and S326C polymorphism of OGG1 gene in postmenopausal women. Molecular Genetics and Metabolism, 104(4), 644-7.

[81] Dlugosz, A., Roszkowska, A., \& Zimmer, M. (2009). Oestradiol protects against the harmful effects of fluoride more by increasing thiol group levels than scavenging hydroxyl radicals. Basic and ClinicalPharmacolology and Toxicology, 105(6), 366-373.

[82] Wen, Y., Doyle, M., Cooke, T., \& Feely, J. (2000). Effect of menopause on low density lipoprotein oxidation: is estrogen an important determinant? Maturitas, 34, 233-238.

[83] Subbiah, M. T., Kessel, B., Agrawal, M., Rajan, R., Abplanalp, W., \& Rymaszewski, Z. (1993). Antioxidant potential of specific estrogens on lipid peroxidation. The Journal of Clinical Endocrinology and Metabolism, 77, 1095-1097.

[84] Kassia, E., Dalamagaa, H., Hroussalasa, G., Kazanisa, K., Merantz, A., \& Zacharic, E. J. (2010). Giamarellos-Bourbouli, A. Dionyssiou-Asterioua. Adipocyte factors, highsensitive C-reactive protein levels and lipoxidative stress products in overweight postmenopausal women with normal and impaired OGTT. Maturitas, 67, 72-77.

[85] Arteaga, E., Rojas, A., Villaseca, P., Bianchi, M., Arteaga, A., \& Duran, D. (1998). In vitro effect of oestradiol, progesterone, testosterone, and of combined estradiol/ progestins on low density lipoprotein (LDL) oxidation in postmenopausal women. Menopause, 5(1), 16-23.

[86] Bureau, I., Laporte, F., Favier, M., Faure, H., Fields, M., Favier, A. E., \& Roussel, A. M. (2002). No antioxidant effect of combined HRT on LDL oxidizability and oxidative stress biomarkers in treated post-menopausal women. Journal of the American College of Nutrition, 21(4), 333-8.

[87] Akcay, T., Dincer, Y., Saygili, E. I., Seyisoğlu, H., \& Ertunğalp, E. (2010). Assessment of DNA nucleo base oxidation and antioxidant defense in postmenopausal women under hormone replacement therapy. Indian Journal of Medical Sciences, 64(1), 17-25.

[88] Leal, H.M., Abellán, A.J., Carbonell, M.L.F., Díaz, F.J., García, S.F.A., \& Martínez, S.J.M. Influence of the presence of hot flashes during menopause on the metabolism 
of nitric oxide. Effects of hormonal replacement treatment. Medicina Clínica (Barc) 200022, 114(2), 41-5.

[89] Itabe, H. (2003). Oxidized low-density lipopropteins: What is understood and what remains to be clarified. Biological and Pharmaceutical Bulletin, 26(1), 1-9.

[90] Mackness, M. I., Mackness, B., Durrington, P. N., Connelly, P. W., \& Hegele, R. A. (1996). Paraoxonase: biochemistry, genetics and relationship to plasma lipoproteins: Current Opinionin Lipidology,, 7, 69-76.

[91] Aviram, M., Rosenblat, M., Bisgaier, C. L., Newton, R. S., Primo, P. S. L., \& La Du, B. N. (1998). Paraoxonaseinhibitis high-density lipoprotein oxidation and preserves its function. The Journal of ClinicalInvestigaction, 101, 1581-1590.

[92] Crane, T. E., Kubota, C., West, J. L., Kroggel, M. A., Wertheim, B. C., \& Thomson, C. A. (2011). Increasing the vegetable intake dose is associated with a rise in plasma carotenoids without modifying oxidative stress or inflammation in overweight or obese postmenopausal women. Journal of Nutrition, 141(10), 1827-33.

[93] Scoglio, S., Benedetti, S., Canino, C., Santagni, S., Rattighieri, E., Chierchia, E., Canestrari, F., \& Genazzani, A. D. (2009). Effect of a 2-month treatment with Klamin, a Klamath algae extract, on the general well-being, antioxidant profile and oxidative status of postmenopausal women. GynecologicalEndocrinology, 25(4), 235-40.

[94] Miquel, J., Ramírez, B. A., Ramírez, B. J., \& Diaz, A. J. (2006). Menopause: A review on the role of oxygen stress and favorable effects of dietary antioxidants. Archives of Gerontology and Geriatrics, 42, 289-306.

[95] Beavers, K. M., Serra, M. C., Beavers, D. P., Cooke, M. B., \& Willoughby, D. S. (2009). Soymilk supplementation does not alter plasma markers of inflammation and oxidative stress in postmenopausal women. Nutrition Research, 29(9), 616-22.

[96] Giovannelli, L., Pitozzi, V., Luceri, C., Giannini, L., Toti, S., Salvini, S., Sera, F., Souquet, J. M., Cheynier, V., Sofi, F., Mannini, L., Gori, A. M., Abbate, R., Palli, D., \& Dolara, P. (2011). Effects of de-alcoholised wines with different polyphenol content on DNA oxidative damage, gene expression of peripheral lymphocytes, and haemorheology: an intervention study in post-menopausal women. European Journal of $\mathrm{Nu}$ trition, 50(1), 19-29.

[97] Azadbakht, L., Kimiagar, M., Mehrabi, Y., Esmaillzadeh, A., Hu, F. B., \& Willett, W. C. (2007). Dietary soya intake alters plasma antioxidant status and lipid peroxidation in postmenopausal women with the metabolic syndrome. British Journal of Nutrition, 98(4), 807-13.

[98] Salvini, S., Sera, F., Caruso, D., Giovannelli, L., Visioli, F., Saieva, C., Masala, G., Ceroti, M., Giovacchini, V., Pitozzi, V., Galli, C., Romani, A., Mulinacci, N., Bortolomeazzi, R., Dolara, P., \& Palli, D. (2006). Daily consumption of a high-phenol extra-virgin olive oil reduces oxidative DNA damage in postmenopausal women. British Journal of Nutrition, 95(4), 742-51. 
[99] Dickman, J. R., Koenig, R. T., \& Ji, L. L. (2009). American ginseng supplementation induces an oxidative stress in postmenopausal women. Journal of the American of College of Nutrition, 28(2), 219-28.

[100] Garcia P.M.C. (2008). Antioxidantes en la dietamediterranea. Nutrición Clínica en Medicina, 2(3), 129-140.

[101] Agarwal, S., \& Rao, A. V. (2000). Tomato lycopene and its role in human health and chronic diseases. Canadian Medical Association or its licensors, 163(6), 739-44.

[102] Waliszewski, K. N., \& Blasco, G. (2010). Propiedadesnutraceúticasdellicopeno. SaludPublica Mexicana, 52, 254-265.

[103] Palasuwan, A., Margaritis, I., Soogarun, S., \& Rousseau, A. S. (2011). Dietary intakes and antioxidant status in mind-body exercising pre- and postmenopausal women. The Journal of Nutrition Health and Aging, 15(7), 577-84.

[104] Karolkiewicz, J., Michalak, E., Pospieszna, B., Deskur-Smielecka, E., Nowak, A., \& Pilaczyńska-Szcześniak, Ł. (2009). Response of oxidative stress markers and antioxidant parameters to an 8week aerobic physical activity program in healthy, postmenopausal women. Archives of Gerontology and Geriatrics 49(1)e67-71.

[105] Schmitz, K. H., Warren, M., Rundle, A. G., Williams, N. I., Gross, M. D., \& Kurzer, M. S. (2008). Exercise effect on oxidative stress is independent of change in estrogen metabolism. Cancer Epidemiology Biomarkers and Prevention, 17(1), 220-3.

[106] Pialoux, V., Brown, A. D., Leigh, R., Friedenreich, C. M., \& Poulin, M. J. (2009). Effect of cardiorespiratory fitness on vascular regulation and oxidative stress in postmenopausal women. Hypertension, 54(5), 1014-20.

[107] Lwow, F., Dunajska, K., Milewicz, A., Jedrzejuk, D., Kik, K., \& Szmigiero, L. (2011). Effect of moderate-intensity exercise on oxidative stress indices in metabolically healthy obese and metabolically unhealthy obese phenotypes in postmenopausal women: a pilot study. Menopause, 18(6), 646-53. 